\title{
Merkel cell carcinoma in an immunosuppressed patient ${ }^{*}$
}

\author{
Heliana Freitas de Oliveira Góes ${ }^{1}$ \\ Maria Cláudia de Almeida Issa ${ }^{1}$ \\ Luciana Pantaleão ${ }^{2}$
}

\author{
Caren dos Santos Lima ${ }^{1}$ \\ Flávio Barbosa Luz ${ }^{1}$ \\ José Gabriel Miranda da Paixão ${ }^{3}$
}

DOI: http:/ / dx.doi.org/10.1590/abd1806-4841.20175510

\begin{abstract}
Merkel cell carcinoma is an uncommon neuroendocrine carcinoma with a rising incidence and an aggressive behavior. It predominantly occurs in older patients, with onset occurring at a mean age of 75-80 years. Recognized risk factors are ultraviolet sunlight exposure, immunosuppression, and, more recently, Merkel cell polyomavirus. We report a case of Merkel cell carcinoma in a young HIV positive patient with Merkel Cell polyomavirus detected in the tumor.
\end{abstract}

Keywords: Carcinoma, Merkel cell; Merkel cell polyomavirus; HIV seropositivitys

\section{INTRODUCTION}

Merkel cell carcinoma (MCC) is an uncommon neuroendocrine carcinoma with a rising incidence and an aggressive behavior that mostly arises in sun exposed areas. The head and neck are the most affected sites, followed by the trunk and limbs. ${ }^{1}$ It predominantly occurs in older patients, with onset occurring at a mean age of 75-80 years with a male predilection. ${ }^{2}$ Only $5 \%$ of cases occur in patients under 50 years. Recognized risk factors are ultraviolet (UV) sunlight exposure and immunosuppression. More recently, Merkel cell polyomavirus ( $M C P y V)$ has also been identified as a causative agent. ${ }^{3}$ We report an aggressive evolution case of MCC in a young HIV positive patient with $M C P y V$ detected in the tumor.

\section{CASE REPORT}

We report a 46-year-old Caucasian man presented with an asymptomatic mass on the face with a 4-week history of rapid growth (Figure 1). Physical examination revealed an erythematous
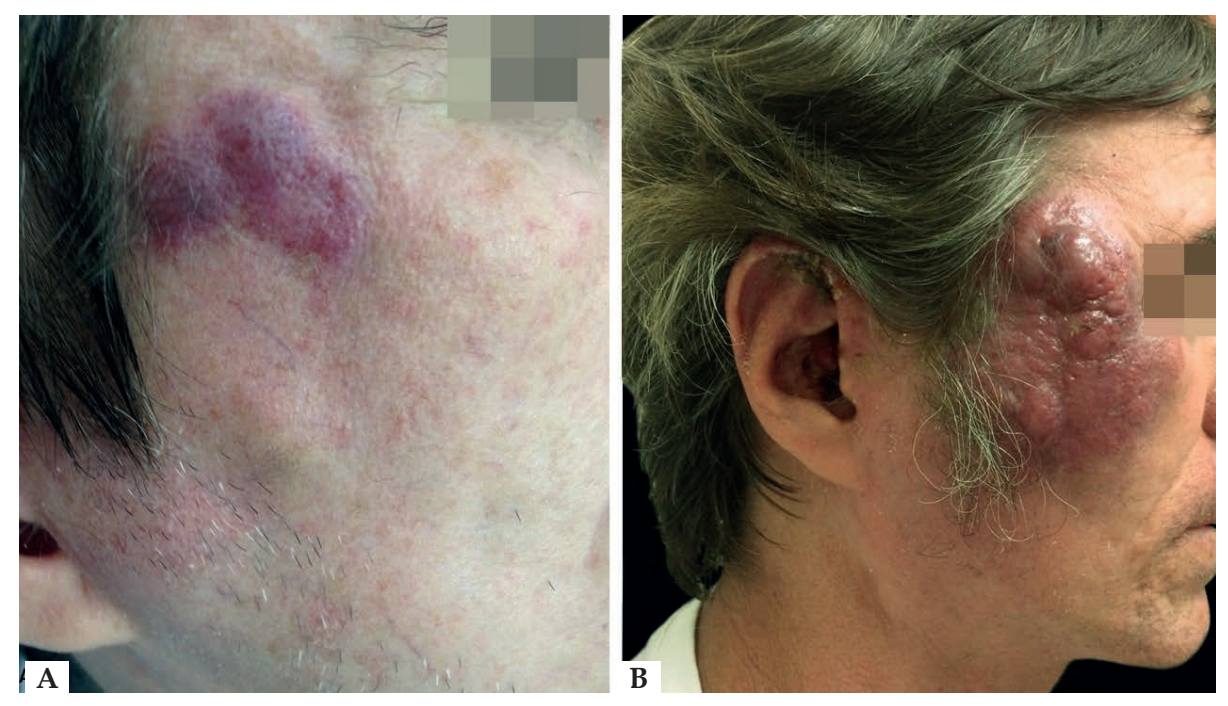

Figure 1:

A - Erythematous and purple infiltrated plaque. B- Rapid growth after six weeks: $10 \times 7 \mathrm{~cm}$ infiltrated erythematous-purplish mass

\footnotetext{
Received on 15.12.2015

Approved by the Advisory Board and accepted for publication on 15.02.2016

* Work performed at Hospital Universitário Antônio Pedro - Universidade Federal Fluminense (HUAP-UFF) - Niterói (RJ), Brazil.

Financial support: none.

Conflict of interest: none.
}

Department of Dermatology, Universidade Federal Fluminense (UFF) - Niterói (RJ), Brazil.

Department of Pathology, Universidade Federal Fluminense (UFF) - Niterói (RJ), Brazil.

Department of Head and Neck Surgery, Instituto Nacional de Câncer (INCA) - Rio de Janeiro (RJ), Brazil.

C2017 by Anais Brasileiros de Dermatologia 
and purple infiltrated plaque, $25 \times 10 \mathrm{~mm}$, adhered to the deep layers in the right temporal region. We observed no ulceration or other abnormalities of the overlying skin. We also observed some preauricular and submandibular lymph nodes. His medical history included HIV infection, under treatment with zidovudine, lamivudine, and efavirenz. Multiples basal cell carcinomas had been previously excised.

Tumor cells were positive for AE1/AE3 and cytokeratin 20 (CK-20), and negative for CD45 (Figures 2 and 3). MCPyV was detected in the tumor by polymerase chain reaction (PCR). A CT scan of the head and neck showed a tumor formation in the right temporal region involving the skin and deep layers, as well as parotid lymph node enlargement (Figure 4). The tumor was stage III according to the TNM staging system. It was considered unresectable due to lymphangitic carcinomatosis. The patient is being followed at the palliative care sector.

\section{DISCUSSION}

MCC generally occurs in late adulthood as an asymptomatic, rapidly growing, pink-red or violaceous, firm solitary papule or nodule, usually on the head or neck, but also on the extremities
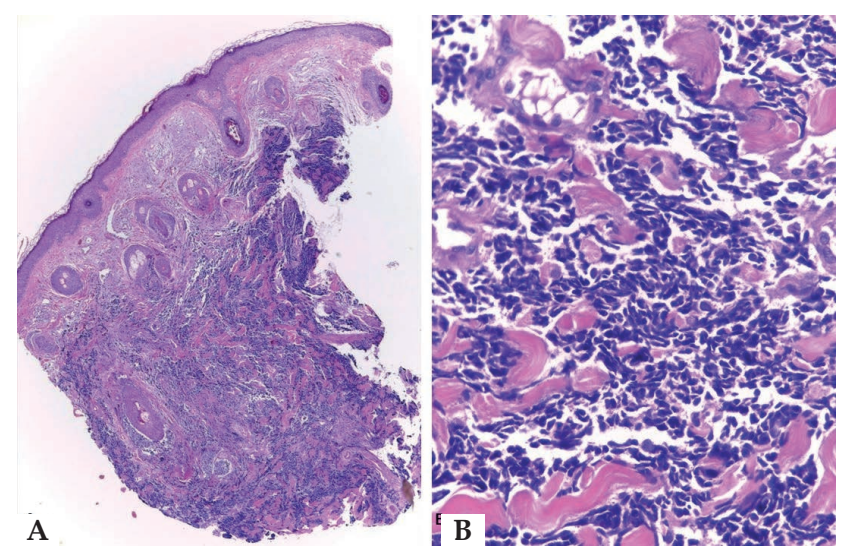

Figure 2: A - Skin fragment with intense dermal infiltration by neoplastic cells and dissociating collagen fibers (Hematoxylin \& eosin, 40X). B - Small cells with scant cytoplasm and irregular and hyperchromatic nuclei (Hematoxylin \& eosin, 400X) or buttocks. ${ }^{4}$ Significant clinical characteristics of this tumor have been summarized in an acronym: AEIOU (Asymptomatic, Expanding rapidly, Immune compromised, Older than 50, and UV-exposed, fair skin..). ${ }^{5,6}$

MCC, which like melanoma appears to be derived from neural crest progenitor cells, occurs at an increased incidence in HIV-infected individuals and transplant recipients than in the general population. ${ }^{7}$ In this case, in addition to our patient being HIV positive, MCC had a very aggressive evolution.

Recently, a new human tumor virus of the Polyomaviridae family has been discovered. This virus, known as Merkel cell polyomavirus, is part of the human viral flora but can launch cancer if it acquires a set of mutations in a susceptible host (elderly, patients with hematological malignancies or immunosuppression). Infection with $M C P y V$ usually occurs early in childhood and is asymptomatic. Under very specific conditions like loss of immune surveillance, virus genome may clonally integrated into the host's genome. The integrated viral genome frequently contains specific truncating mutations in viral tumor antigen ( $\mathrm{T}$ antigen) that prevent virus replication within the cells and disturb cellular signaling pathways. When this occurs, tumor formation takes place..$^{5,6,8}$

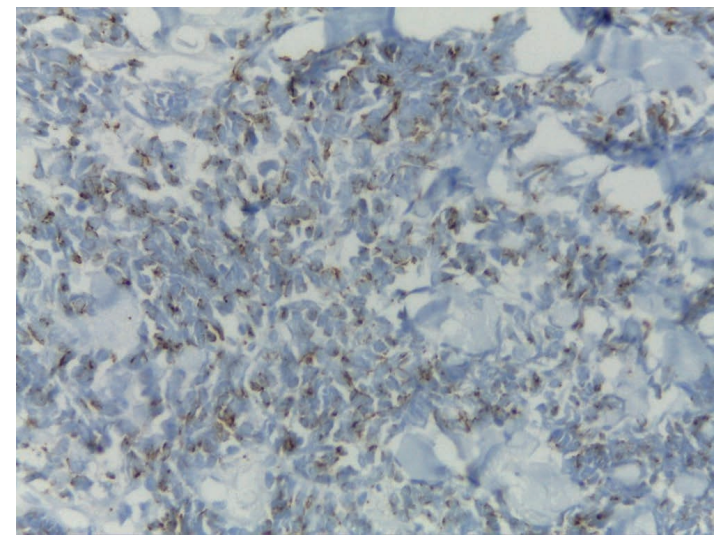

FIGURE 3: Neoplastic cells show positivity for anti-cytokeratin antibody 20 (CK20; 400X)

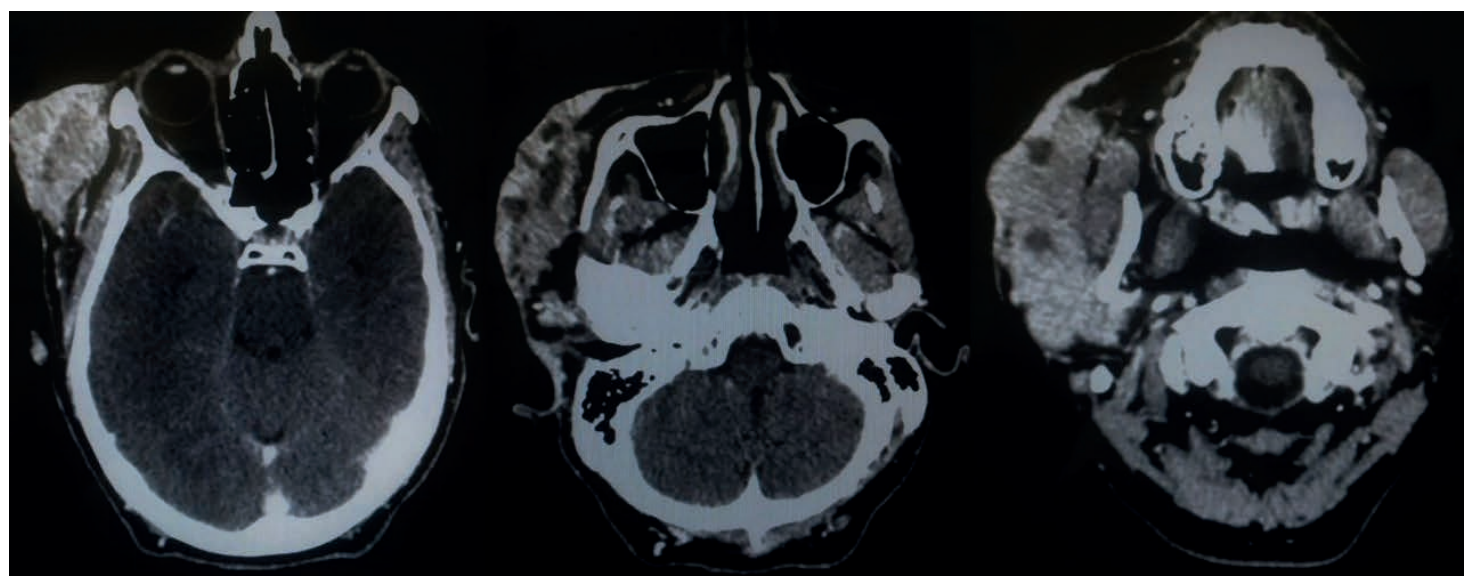

Figure 4:

Tumor of irregular contours with areas suggestive of necrosis in the right temporal region. Lesion extends into subcutaneous tissue and deep layers including masseter muscle and parotid gland. Lymph node enlargement in the cervical and parotid regions 
Histopathological differential diagnosis of the MCC includes basal cell carcinoma, poorly differentiated squamous cell carcinoma, melanoma, lymphoma, eccrine carcinoma, metastatic neuroblastoma, and primary peripheral primitive neuroectodermal tumor. ${ }^{9}$

Immunohistochemically, the tumor shows epithelial and neuroendocrine differentiation. CK-20 is a sensitive and quite specific marker for MCC. Markers of neuroendocrine differentiation include chromogranin a, synaptophysin, neuron-specific enolase. MCC also expresses CD117, the KIT receptor tyrosine kinase and, in approximately a third of cases, CD99.6,9

MCC has an aggressive course with early hematogenous and lymphatic spread. Since the tumor often remains asymptomatic for some time, spread has occurred in most cases at the time of diagnosis. In cutaneous cases of MCC, a local recurrence rate of $11-45 \%$ is reported. About $55-60 \%$ of the cases develop positive lymph nodes. Distant metastases, mostly to lung, liver, bones and brain, occur in about $35 \%{ }^{2,9}$

We report a case of MCC in an HIV positive patient with $M C P y V$. Our case report highlights the importance of thorough histologic evaluation of clinically suspicious lesions, like MCC, especially in immunosuppressed patients. Ongoing investigation of the oncogenic role of $\mathrm{MCP} Y \mathrm{~V}$ in pure and combined MCC may facilitate the development of adjuvant treatment modalities including targeted immunostimulation.

\section{REFERENCES}

1. Tothill R, Estall V, Rischin D: Merkel cell carcinoma: emerging biology, current approaches, and future directions. Am Soc Clin Oncol Educ Book. 2015:e519-26.

2. Albores-Saavedra J, Batich K, Chable-Montero F, Sagy N, Schwartz AM, Henson DE. Merkel cell carcinoma demographics, morphology, and survival based on 3870 cases: a population based study. J Cutan Pathol. 2010;37:20-7.

3. Girschik J, Thorn K, Beer TW, Heenan PJ, Fritschi L. Merkel cell carcinoma in Western Australia: a population-based study of incidence and survival. $\mathrm{Br} \mathrm{J}$ Dermatol. 2011:165:1051-7.

4. Schick BA, Tobe JS, Joseph MG, Rouse TB, Gabril MY. Incidental Merkel cell carcinoma in a cutaneous horn: a case report. Dermatol Pract Concept. 2015;5:47-50.

5. Sadeghi F, Ghanadan A, Salehi Vaziri M1, Bokharaei Salim F, Monavari SH, Keyvani $\mathrm{H}$. Merkel cell polyomavirus infection in a patient with Merkel cell carcinoma: a case report. Jundishapur J Microbiol. 2015;8:e17849.

6. Heath M, Jaimes N, Lemos B, Mostaghimi A, Wang LC, Peñas PF, et al. Clinical characteristics of Merkel cell carcinoma at diagnosis in 195 patients: the AEIOU features. J Am Acad Dermatol. 2008:58:375-81.

7. Lanoy E, Dores GM, Madeleine MM, Toro JR, Fraumeni JF, Engels EA. Epidemiology of non-keratinocytic skin cancers among persons with acquired immunodeficiency syndrome in the U.S. AIDS. 2009;23:385-93.

8. Foulongne V, Sauvage V, Hebert C, Dereure O, Cheval J, Gouilh MA, et al. Human skin microbiota: high diversity of DNA viroses identified on the human skin by high throughput sequencing. PLoS One. 2012;7:e38499.

9. Roy S, Das I, Nandi A, Roy R. Primary Merkel cell carcinoma of the oral mucosa in young adult male: Report of a rare case. Indian J Pathol Microbiol. 2015;58:214-6.

\author{
MAILING ADDRESS: \\ Heliana Freitas de Oliveira Góes \\ Rua Itararé, 177- Bela Vista \\ 01308-030 - São Paulo - SP \\ Brazil \\ E-mail: heliana_g@yahoo.com.br
}

How to cite this article: Góes HFO, Lima CS, Issa MCA, Luz FB, Pantaleão L, Paixão JGM. Merkel cell carcinoma in an immunosuppressed patient. An Bras Dermatol. 2017;92(3):386-8. 